\title{
Use of Social Media Tool "Whatsapp" in Medical Education
}

\author{
Qudsia Anwar Dar, ${ }^{1}$ Farooq Ahmad, ${ }^{2}$ Muhammad Ramzan, ${ }^{3}$ Sadaf Humayun Khan, ${ }^{4}$ Khadija Ramzan, \\ Waqar Ahmed, ${ }^{6}$ Zahid Kamal $^{7}$
}

\begin{abstract}
We are living in an era of technology where smart phones and hence social media has entered into many aspects of our life. Many professions are using social media to improve communication between colleagues. Social media tools are gaining attention in medical education as well.
\end{abstract}

Objective: To explore the potential of WhatsApp as an instructional strategy for $4^{\text {th }}$ Year MBBS students in Ophthalmology.

Methods: We made two groups of students on WhatsApp one for males and one for females. Topic of lecture, relevant images of taught topic and MCQs and SEQs were shared in both groups and students were encouraged to ask questions if they had any. After ten

\footnotetext{
${ }^{1}$ Women Medical Officer, Department of Ophthalmology, Mayo Hospital, Lahore.

${ }^{2}$ Medical Office, Department of Ophthalmology

Mayo Hospital, Lahore.

${ }^{3}$ Assistant Professor of Ophthalmology

KEMU/Mayo Hospital, Lahore.

${ }^{4}$ Medical Officer, Department of Ophthalmology

Mayo Hospital, Lahore.

${ }^{5}$ Mphil Statistics

${ }^{6}$ Medical Officer, Department of Ophthalmology

Mayo Hospital, Lahore.

${ }^{7}$ Professor of Ophthalmology

KEMU/ Mayo Hospital, Lahore.
}

\section{Date of Submission: 01-06-2016}

Date of Acceptance for publication: 18-01-2017

Conflict of Interest: None

Funding Source: None

\section{Contribution}

All Authors have contributed in Study Design, Data Collection, Data Analysis, Data Interpretation, Manuscript Writing and Approval. lectures the students were asked to give their feedback on our activity of WhatsApp group on an anonymous questionnaire.

Results: Two hundred and thirty four students, 145 $(62.0 \%)$ female and $86(36.8 \%)$ males students filled in the anonymous questionnaire. One hundred and eighty nine students $(88.77 \%)$ were using social media to learn medicine while 45 students $(19.23 \%)$ were not. Sixty seven students $(29.39 \%)$ were using both WhatsApp and Facebook, 65 students $(28.51 \%)$ were using Facebook, 57 students (25\%) were using WhatsApp. Sixty percent of students were using social media once or more than twice a day. Eighty eight (63.8\%) female students and $66(77.7 \%)$ male students ranked this activity as high or above. To the open ended question we got appreciative comments and some suggestion.

Conclusion: WhatsApp is an effective social media tool to motivate, augmentand perhaps improve the learning of undergraduates in addition to traditional teaching.

Key Words: WhatsApp, medical education, smartphones.

\section{Introduction}

We are living in an era of technology where smart phones and hence social media has entered into many aspects of our life. Many professions are using social media to improve communication between colleagues. Nowadays most people have smart phones and there are many messenger applications available. ${ }^{1}$

WhatsApp is a messenger application that has variety of functions, like text messages, images, audio files, video files, and links to web addresses. ${ }^{2}$ A unique feature of this application is the option to create a group. The one who makes the group becomes the 
admin of that particular group, who can add and remove the group members. All participants in the group have equal rights and they can exit the group if they want. Participants receive an alert for each messages hared, they can also mute the in-coming alerts for the duration of 8 hours, a day, a whole week or an year.

Social media tools are gaining attention in medical education as well. WhatsApp can be used to improve the interaction between students and teachers for motivation and learning. ${ }^{3}$

In general teachers don't like use of mobile phones in learning environment as they feel that it is disturbing instead of being useful for education. Some teachers do not show any enthusiasm to use it in teaching practices.

The rationale of this study is to explore the potential of WhatsApp as an Instructional Strategy for the $4^{\text {th }}$ Year MBBS Students in Ophthalmology.

\section{Methods}

This cross sectional study was performed among $4^{\text {th }}$ year MBBS students of King Edward Medical University Lahore from January to march 2016. We made two groups of students on WhatsApp one for males and one for females. Both groups included 6 faculty members of eye department. There were 136 participants in male group and this group was named as department of ophthalmology KEMU. The female group was named as MBBS ophthalmology KEMU $4^{\text {th }}$ year with 163 participants. All students participated willingly and they were free to exit the group if they wanted so. The students were told about the norms of groups like there will be academic discussion on this forum and no cross talk and personal remarks are allowed.

Topic of lecture was shared with both groups beforehand so that students might come prepared and understand the subject better. After the lecture relevant images of taught topic were shared in both groups and students were encouraged to ask questions if they had any. Moreover MCQs and SEQs were also shared. Pictures of patients with important clinical findings were also shared and students were asked to respond. After 24 hours the correct answers were shared by the faculty. After ten lectures the students were asked to give their feedback on our activity of WhatsApp group and mobile learning. Data collection tool was an anonymous self administered questionnaire with four close ended questions. There was one open ended question for student's comments and suggestions. Following were the questions in the questionnaire.
Do you use social media for medical education?

How often do you use it?

Which type of social media do you use?

How do you rank the WhatsApp group activity by our department?

Ranking was on a six point scale with 1 being the lowest and 6 being the highest.

Open ended question was asked to give their comments and suggestions.

Two hundred and thirty four students filled in the questionnaire and the quantitative data was analyzed by using SPSS 13.0.Descriptive statistics were used to calculate frequency and percentages for categorical variables.

\section{Results}

Two hundred and thirty four students, 145 (62.0\%) female and $86(36.8 \%)$ males students filled in the anonymous questionnaire. Three students did not mention their gender.

One hundred and eighty nine students (88.77\%) mentioned that they use social media to learn medicine while 45 students (19.23\%) mentioned that they do not. The break up is shown in Figure 1.

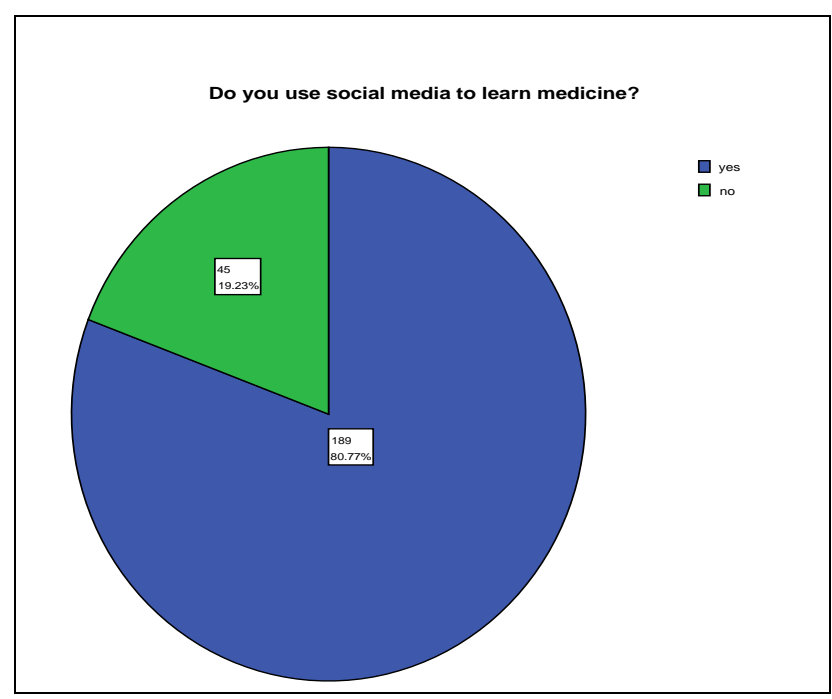

Fig. 1: Percentages of Students using Social Media to Learn Medicine.

Sixty seven students $(29.39 \%)$ were using both WhatsApp and Facebook, 65 students $(28.51 \%)$ were using Facebook, 57 students (25\%) were using WhatsApp as shown in Figure 2. The frequency of social medial usage was such that $105(46.26 \%)$ students 
were using it more than twice a day, $33(14.54 \%)$ students once a day, 18 (7.93\%) students 2 to 3 times a week and $71(31.28 \%)$ students occasionally as shown in figure 3. Results of students' ranking of our WhatsApp group activity are shown in Table 1. Eighty eight (63.8\%) female students and $66(77.7 \%)$ male students ranked this activity as high or above.

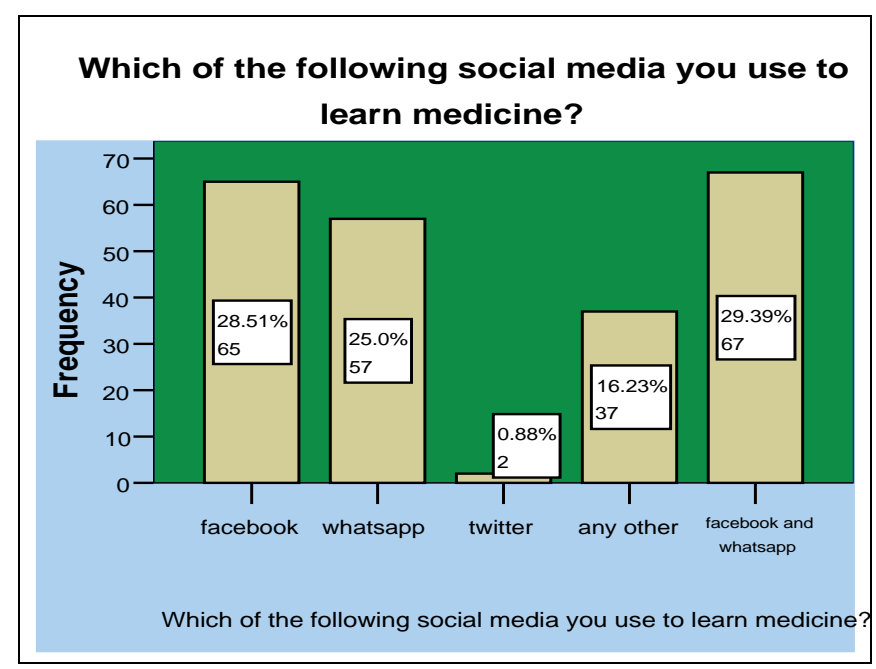

Fig. 2: Frequencies and Percentages of Type of Social Media used by Medical Students.

To the open ended question we got appreciative comments and some suggestion like we should create a Facebook page as well, create smaller groups as well, other departments should also make such groups, timing of post should not be very late night, nonmedical stuff should not be posted.

\section{Discussion}

Our study evaluated the potential of WhatsApp as an instructional strategy for fourth year MBBS students at

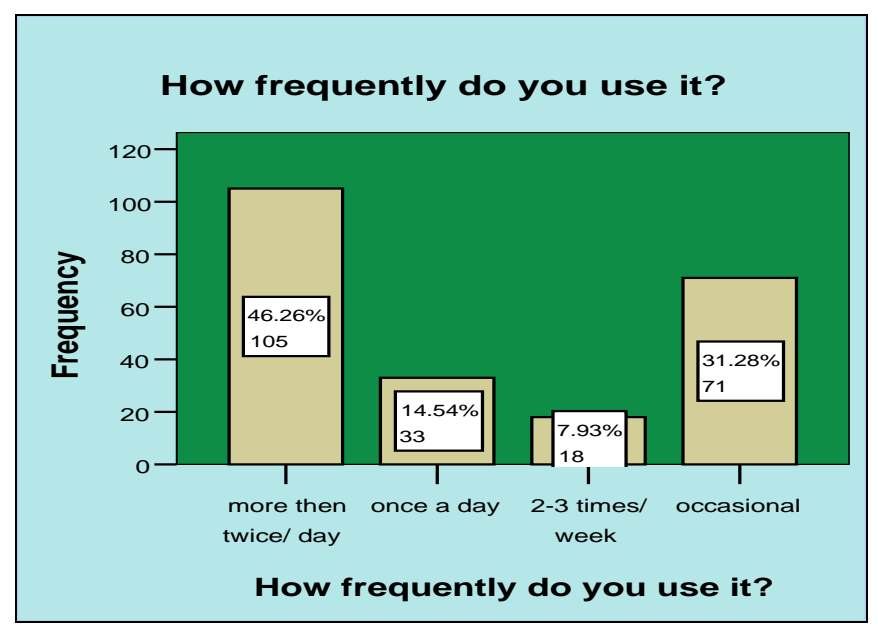

Fig. 3: Frequency of social media usage by the students.

King Edward Medical University Lahore. We found that WhatsApp was the most commonly used social media by our students. Sixty nine percent of the students ranked WhatsApp group activity high or above in helping them learn ophthalmology.

Results of our study are supported by previous studies done by many researches on the role of mobile phone learning in medical education. ${ }^{1}$ A study was done by Rambe and Bere on using mobile instant messaging to leverage learner participation and transform pedagogy at a South African University of Technology. ${ }^{4}$ They reported a positive feedback from students on WhatsApp learning. Their students also found it a good tool to increase the motivation towards learning and it can help bridge the gaps in knowledge. Similarly a study done in Spain by Plana examined the use of WhatsApp in improving the reading skills of English language. ${ }^{5}$ They reported that WhatsApp was motivational and it also increased the enthusiasm for reading in a foreign language.

Another study done by AichaBlehchAmry ${ }^{6}$

Table1:

\begin{tabular}{|c|c|c|c|c|c|l|l|l|}
\hline \multirow{3}{*}{} & & \multicolumn{6}{|c|}{ How do you rank WhatsApp group created by eye department KEMU } & \multirow{2}{*}{ Total } \\
\cline { 3 - 8 } & & Lowest & Lower & Low & High & Higher & Highest & \\
\cline { 2 - 8 } Gender & Male count & 8 & 4 & 7 & 19 & 22 & 25 & 85 \\
& percent & $9.4 \%$ & $4.7 \%$ & $8.2 \%$ & $22.4 \%$ & $25.9 \%$ & $29.4 \%$ & $100.0 \%$ \\
\cline { 2 - 8 } & Female count & 14 & 8 & 28 & 44 & 31 & 13 & 138 \\
& percent & $10.1 \%$ & $5.8 \%$ & $20.3 \%$ & $31.9 \%$ & $22.5 \%$ & $9.4 \%$ & $100.0 \%$ \\
\hline \multirow{2}{*}{ Total } & count & 22 & 12 & 35 & 63 & 53 & 38 & 223 \\
& percent & $9.9 \%$ & $5.4 \%$ & $15.7 \%$ & $28.3 \%$ & $23.8 \%$ & $17.0 \%$ & $100.0 \%$ \\
\hline
\end{tabular}


showed that WhatsApp learning was favoured by female students as they found it easy to interact with their teachers as compared to face to face learning. While this not the case in our study that shows that males students ranked it better as compared to female students. This shows that females students prefer the traditional teaching over the mobile learning.

Our students also found learning at anytime and at anyplace as fun, as they were able to learn in their relax time. Howere there are some potential challenges in mobile based learning like superficial learning, distraction from text books, privacy of information and expense $^{7}$. We acknowledge that students not having smart phones will not be able to benefit from it.

It creates a virtual learning environment. It can also be used to give mock assessments like SEQs and MCQs. Moreover not only the learners interact with faculty but also get advantage of peer assisted learning (PAL). We kept male and female learners separate to meet our cultural requirements of segregation. However the useful educational material was copy-pasted to either group by the faculty.

Our study is a pilot project and it throws open opportunities for further research in exploring the benefits of WhatsApp mobile learning. Moreover multi centered randomized trials should be conducted to prove the beneficiary role of WhatsApp learning in medical education. We also suggest that the university can make certain guidelines for use of mobile application in medical education to cope up with the challenges associated with it.

\section{Conclusion}

WhatsApp is an effective social media tool to motivate, augment and perhaps improve the learning of undergraduates in addition to traditional teaching. Further studies are needed for its adoption and responsible integration into medical education.

\section{References}

1. Tulika B, Dhanajay J. a study of students experience of WhatsApp mobile learning .global journol of humansocial science research. H. 2014; 14: (4).

2. Bouhnik D, Deshen M. WhatsApp goes to school: Mobile instant messaging between teachers and students. Journal of Information Technology Education: Research. 2014; 13: 217-231.

3. Zurita G, Nussbaum M. A conceptual framework based on activity theory for mobile CSCL. Br J Educ Technol. 2007; 38 (2): 11-35.

4. Rambe P,Bere A. Using mobile instant messaging to leverage learner participation and transform pedagogy at a South African University of Technology. British Journal of Educational Technology. 2013; 44 (4): 544561.

5. Plana MGC, Escofet MIG, Figueras IT, Gimeno A, Appel C, Hopkins J. Improving learners' reading skills through instant short messages: A sample study using WhatsApp. $4^{\text {th }}$ World-CALL Conference, Glasgow; 2013.

6. AmryAichaBlehch. The impact of whatsapp mobile social learning on the achievement and attitudes of female students compared with face to face learning in the classroom European scientific journal. 2014; 10-22.

7. Ventola CL. Mobile devices and apps for health care professionals: Uses and benefits. P T. 2014; 39 (5):35664. 